\title{
CONTEXTOS DE SOCIALIZAÇÃO FREQUENTADOS POR CRIANÇAS DE QUATRO ANOS EM PORTUGAL: UMA SONDAGEM NACIONAL REALIZADA EM 1988
}

\author{
Joaquim Bairrão \\ Maria Isolina Borges ${ }^{3}$ \\ Isabel Abreu-Lima ${ }^{4}$ \\ Maria Barbosa ${ }^{5}$ \\ Orlanda Cruz \\ Margarida Henriques ${ }^{7}$
}

Resumo: Os contextos de socialização da criança, bem como a sua articulação em rotinas diárias e semanais, desempenham um papel primordial no seu desenvolvimento. Com o objectivo de conhecer a diversidade e organização dos contextos de socialização frequentados pelas crianças de quatro anos em Portugal, foi conduzida em 1988 uma sondagem com uma amostra representativa a nível nacional, no âmbito de um projecto de investigação transnacional. Participaram nesta sondagem 581 famílias com crianças de quatro anos, das quais 298 eram do sexo masculino e 283 do sexo feminino. Os dados foram recolhidos através de uma entrevista face a face realizada no domicílio familiar. Os resultados permitiram caracterizar as rotinas diária e semanal das crianças, nomeadamente os contextos frequentados e suas principais características.

\footnotetext{
${ }^{1}$ Por lapso, este artigo não foi incluído no Vol. XXIII, 2 (2009), Número especial de Homenagem a Joaquim Bairrão, da revista Psicologia. Pelo facto, a direcção da Revista pede desculpa.

Este estudo foi financiado pelo Serviço de Educação da Fundação Calouste Gulbenkian e pela Junta Nacional de Investigação Científica e Tecnológica (JNICT). Este artigo constitui uma versão revista de uma comunicação apresentada pelo Prof. Joaquim Bairrão e restante equipa no Congresso Nacional de Educação Infantil e Básica que se realizou em Braga em Abril de 1990.

2 Faculdade de Psicologia e de Ciências da Educação, Universidade do Porto

${ }^{3}$ Faculdade de Psicologia e de Ciências da Educação, Universidade do Porto

${ }^{4}$ Faculdade de Psicologia e de Ciências da Educação, Universidade do Porto

5 Faculdade de Psicologia e de Ciências da Educação, Universidade do Porto

${ }^{6}$ Faculdade de Psicologia e de Ciências da Educação, Universidade do Porto

${ }^{7}$ Faculdade de Psicologia e de Ciências da Educação, Universidade do Porto
}

PSICOLOGIA, Vol. XXIV (1), 2010, Edições Colibri, Lisboa, pp. 5-15 
Palavras-chave: contextos de socialização infantil, sondagem, rotina diária, rotina semanal

Socialisation settings attended by four-year old children in Portugal: A national survey, 1988 (Abstract): Child socialisation settings as well and the way they intertwine to form daily and weekly routines, play an outstanding role in children's development. In order to know the organization and diversity of Portuguese four-year-olds' socialisation settings, a survey was conducted on a national representative sample, within the scope of a larger international project. 581 four-year old Portuguese children and their families participated in this study: 298 were boys and 283 were girls. A face-to-face interview at the family home was used to collect data. Results characterised children's weekly and daily routines, as well as the settings they attended and their main features.

Keywords: children socialization settings, survey, daily routine, weekly routine

\section{Introdução}

No âmbito da International Association for the Evaluation of Educational Achievement (IEA), já no final da década de 80 , foi desenhado um projecto de investigação transnacional - Pre-primary Project (IEA-PPP) sobre a situação de cuidados prestados às crianças de quatro anos ${ }^{8}$ (Katz, Crahay, Tietze, Wolf, Rossbach, \& Indrasuta, 1984).

O Projecto Pré-Primário enquadra-se numa área de investigação necessariamente complexa - desenvolvimento infantil em contexto - cuja relevância nas sociedades actuais é inegável, já que a função educativa não é apanágio exclusivo da família, sendo partilhada com uma multiplicidade de contextos extra-familiares. É de sublinhar que, à data em que foi realizado, não se conheciam outros estudos no domínio, tendo sido este a lançar a atenção nacional sobre a importância da investigação no domínio da educação pré-escolar.

\footnotetext{
${ }^{8}$ Para além de Portugal, participaram neste projecto os seguintes países: Bélgica, República Federal da Alemanha, Finlândia, Itália, Espanha, Hungria, Nigéria, Tailândia, China, Filipinas, Quénia, Hong-Kong e Estados Unidos da América. A coordenação internacional do projecto foi assumida pela High/Scope Educational Research Foundation, nas pessoas de David Weikart e Patricia Olmsted. A nível da Faculdade de Psicologia e de Ciências da Educação da Universidade do Porto, este foi o primeiro projecto de investigação de âmbito internacional.
} 
A Psicologia do Desenvolvimento e da Educação contribuiu já com um corpo amplo de conhecimentos que permite compreender o processo de desenvolvimento humano, as suas etapas e as tarefas que o indivíduo tem de aprender a desempenhar ao longo da vida. Porém, como afirmava Bronfenbrenner (1979), sabia-se mais acerca das crianças do que acerca dos contextos onde o desenvolvimento se processa, levantando-se então a questão de saber de que forma os diversos contextos de vida do indivíduo influenciam e determinam esse desenvolvimento. Um dos conceitos chave é a qualidade de vida, enquanto produto das várias experiências vivenciadas pela criança nos vários contextos de socialização em que participa.

$\mathrm{O}$ modelo ecológico enquadra as preocupações subjacentes a este estudo, bem como a definição do seu objecto de estudo e a metodologia eleita para o abordar. De acordo com este modelo, o conhecimento do contexto (mais distal ou mais proximal) em que a criança vive é fundamental para percebermos a sua trajectória desenvolvimental ou, seguindo as palavras do próprio Bronfenbrenner, define-se como "o estudo cientifico da progressiva e mútua acomodação, ao longo do curso de vida, entre um organismo biopsicológico muito complexo, activo e em crescimento (...) e as propriedades em mudança dos cenários imediatos que envolvem a pessoa em desenvolvimento, na medida em que esse processo é afectado pelas relações entre cenários e pelos contextos mais vastos em que estes cenários estão inseridos" (Bronfenbrenner, 1993, p. 7).

Um dos objectivos gerais do IEA-PPP foi a análise das dimensões dos diversos contextos de socialização frequentados pelas crianças que contribuem de forma relevante para o seu desenvolvimento e qualidade de vida. São de distinguir a dimensão estrutural (que remete, por exemplo, para o espaço disponível para as crianças e para o ratio adulto-criança), a dimensão processual (que inclui, por exemplo, as interacções verbais e lúdicas) e a dimensão contextual propriamente dita (que se refere à zona habitacional e aos recursos da comunidade, entre outros aspectos).

A fim de dar resposta a este objectivo, foi necessário proceder ao levantamento dos contextos de socialização frequentados pelas crianças de idade pré-escolar, no final dos anos 80 , na medida em que as estatísticas oficiais apenas informavam sobre a taxa de frequência dos contextos formais (Bairrão, Barbosa, Borges, Cruz, \& Macedo-Pinto, 1989), verificando-se lacunas importantes e a vários níveis nos dados disponíveis. Em primeiro lugar, não existia informação relativa às dimensões estrutural, processual e contextual dos contextos formais. A nível dos contextos informais frequentados pelas crianças, havia um desconhecimento total no que dizia respeito à sua identificação e caracterização. Finalmente, ignorava-se a forma como estes contextos, formais e informais, se articulavam nas rotinas diária e semanal das crianças. 
Atendendo a que o processo de socialização ocorre em todo e qualquer contexto, bem como na articulação existente entre os vários contextos pressupostos da teoria ecológica - e que a família é o sistema organizador do quotidiano da criança, esta foi a principal fonte de informação utilizada neste estudo. De facto, a situação de cuidados vivida por cada criança é o resultado da percepção que a família tem dos recursos existentes na comunidade envolvente, assim como das suas próprias possibilidades de organização para assegurar a prestação de cuidados à criança. Por um lado, a família filtra e selecciona os factores ambientais que influenciam a criança e, por outro, organiza os diversos aspectos da sua rotina, em função dos recursos disponíveis. Nesta perspectiva, os conceitos de contexto de socialização e de família, enquanto sistema organizador, constituem o ponto de partida para a compreensão do processo de desenvolvimento da criança.

O IEA-PPP, iniciado em 1986 incluiu três fases (com duração total prevista de 10 anos), cada uma das quais com objectivos específicos. A primeira fase consistiu numa sondagem nacional, com o objectivo de proceder ao levantamento e caracterização da diversidade de contextos de socialização frequentados pelas crianças de quatro anos. A segunda fase foi constituída pelo estudo da qualidade de vida destas crianças e a terceira incidiu sobre o seu acompanhamento longitudinal. Em Portugal apenas se concretizou a Fase 1 do IEA-PPP, entre 1986 e 1990. Ao longo deste trabalho será feita a sua descrição, apresentados alguns dos principais resultados, bem como uma reflexão acerca do contributo inovador deste projecto à data da sua realização.

O objectivo prioritário da Fase 1 foi inventariar todos os contextos de socialização disponíveis para as crianças de quatro anos. Tornava-se crucial que a operacionalização de contexto reflectisse o conceito base de "um padrão de actividades, papéis e relações interpessoais experienciadas pela pessoa em desenvolvimento num dado cenário com características físicas, sociais e simbólicas que encorajam, permitem ou inibem esse envolvimento, em interaç̧ão progressivamente mais complexa com o ambiente imediato e em actividade nesse mesmo ambiente" (Bronfenbrenner, 1993, p.15; Bronfenbrenner \& Morris, 1998, p. 1013). Com efeito, o conceito de contexto foi definido como a combinação entre o local em que a criança está e a pessoa responsável pela criança (Tietze \& Rossbach, 1984). Mais especificamente pretendeu-se: (1) Elaborar uma tipologia de crianças em função dos padrões de contextos frequentados semanalmente; (2) Descrever os diversos tipos de itinerários percorridos pelas crianças durante um dia típico; (3) Identificar as variáveis relativas à família e à comunidade que contribuem para a compreensão dos padrões de rotina encontrados. 


\section{Método}

\section{Amostra}

A constituição da amostra seguiu um processo de estratificação que implicou a caracterização da totalidade dos concelhos de Portugal Continental com base em 57 variáveis socio-económico-demográfico-culturais e a sua distribuição por 23 estratos. Procedeu-se à selecção aleatória de 57 concelhos, dos quais, também aleatoriamente, se escolheram as crianças da amostra a partir dos registos de nascimento. De uma amostra alargada (oversampling) de 760 crianças, com o efeito de uma taxa de atrito de $23,6 \%$, obteve-se uma amostra de 581 famílias com crianças de quatro anos, das quais 298 (51\%) são do sexo masculino e 283 (49\%) são do sexo feminino.

Relativamente ao nível educativo, a maior parte das mães possuía um a quatro anos de escolaridade (56\%), $15 \%$ completou entre 5 e 6 anos, $14 \%$ realizou entre 7 a 9 anos, $8 \%$ frequentou o ensino secundário, $5 \%$ tinha mais de 12 anos de estudo e $2 \%$ eram analfabetas. A distribuição dos pais pelos diversos níveis de escolaridade era bastante semelhante à das mães.

No que se refere à situação profissional, $95 \%$ dos pais e $58 \%$ das mães trabalhavam fora de casa, $3 \%$ dos pais e $7 \%$ das mães desenvolviam a sua actividade profissional em casa, $2 \%$ dos pais estavam desempregados, reformados ou eram estudantes e $35 \%$ das mães eram donas de casa, estudantes ou estavam desempregadas.

\section{Instrumento}

Com o objectivo de recolher informação aprofundada sobre os contextos de socialização frequentados pelas crianças de quatro anos, foi construída a nível transnacional uma entrevista semi-estruturada, a ser conduzida junto da mãe, enquanto pessoa responsável pela organização da rotina da criança. No desenvolvimento do protocolo de entrevista foram tidos em conta três tipos de variáveis:

1. Variáveis de estatuto: características relativamente estáveis da família, como o nível de estudos dos pais, língua falada em casa, dimensão do agregado familiar, etc;

2. Variáveis situacionais relativas à família, caracterizadoras das condições de vida (e.g. número de divisões da casa, conforto da habitação, existência de zonas de recreio) e da percepção das necessidades e recursos (situação de cuidados desejada, custos e condições de acesso aos contextos extra-familiares, serviços prestados por esses contextos, etc.); 
3. Variáveis processuais relativas às experiências vividas pelas crianças durante o dia, incluindo a rotina diária, características das várias situações de cuidados e ainda as actividades que os pais realizam com as crianças. saber:

O guião da entrevista foi constituído por oito conjuntos de questões, a

a) Estrutura da família: enumeração de todas as pessoas que pertencem ao agregado familiar, indicando para cada uma a relação com a criança, o sexo e a idade

b) Situação de cuidados da criança: identificação dos contextos frequentados e caracterização do modo como são utilizados (tempo no contexto, pagamento, refeições, distância, etc.)

c) Situações de cuidados desejadas pelos pais

d) Actividades pais-filhos

e) Grelha de rotina diária: quadro de dupla entrada em que se pede à mãe que identifique, para cada hora do dia, o contexto em que o filho se encontra

f) Condições de habitação: caracterização da zona residencial e do grau de conforto da habitação

g) Estatuto de saúde da criança

h) Situação socio-profissional dos pais

\section{Procedimento}

As entrevistas foram realizadas entre Abril e Junho de 1988, no domicílio das famílias, por licenciados em Psicologia, previamente treinados para este efeito. Cada entrevista teve uma duração média de uma hora.

\section{Resultados}

Em primeiro lugar serão apresentados os resultados relativos às rotinas semanais das crianças, ou seja, os contextos utilizados pelas crianças numa base regular durante a semana. Seguidamente, proceder-se-á a uma caracterização vertical, tomando em conta as suas rotinas diárias. Recorde-se que o contexto de socialização se define pela combinação do local e pessoa responsável.

\section{Rotina semanal}

Tendo em vista a exploração dos dados relativos à rotina semanal, será feita uma apresentação do número e tipo de contextos frequentados, das 
razões apontadas pela mãe para a sua escolha, bem como das características de frequência do contexto principal (definido mais à frente).

Foi possível constatar que cerca de $30 \%$ das crianças da amostra (171 crianças) permaneciam exclusivamente com a mãe, na sua própria casa. Das restantes 410 crianças, cerca de $49 \%$ frequentavam um contexto extra-materno, cerca de $18 \%$ frequentavam dois contextos extra-maternos e 3\% frequentavam três ou mais contextos extra-maternos, até um máximo de quatro.

No grupo de crianças que permanecia em casa exclusivamente com a mãe, esta foi questionada acerca dos motivos pelos quais era a única pessoa a tomar conta da criança ao longo do dia e da semana, podendo apresentar até um máximo de três razões. A principal razão apresentada por 110 mães $(64,3 \%)$ foi o facto de se encontrar em casa e, como tal, estar disponível para tomar conta da criança. A segunda razão mais importante e usada por 65 mães $(38 \%)$ foi a inexistência de alternativas para cuidar da criança. Em terceiro lugar surgiu como justificação a vontade expressa da mãe em assumir o papel de cuidadora principal, o que aconteceu com 57 mães (33.3\%). O custo elevado de outras alternativas foi a razão apresentada por 29 mães $(16.9 \%)$. Finalmente, surgiram outras razões relativas à criança e relativas aos contextos disponíveis, as primeiras usadas por 17 mães e as segundas por 6 mães $(9.9 \%$ e $3.5 \%$, respectivamente). Este grupo de crianças era aquele cujos pais possuíam habilitações académicas mais baixas e em que predominavam as categorias profissionais mais indiferenciadas e um maior número de mães domésticas.

No grupo de 289 crianças que frequentavam apenas um contexto extra-materno durante a semana, foi possível verificar que em $32 \%$ dos casos este contexto era o jardim-de-infância e que nos restantes $68 \%$ era um contexto informal.

Os locais mais frequentemente referidos pelas mães como aqueles onde as crianças permaneciam numa base regular durante a semana eram, por ordem de importância, o jardim-de-infância, a casa da criança, a casa de familiares, outras casas, e o parque. O jardim-de-infância era a opção mais desejada pela quase totalidade das famílias.

Quando o jardim-de-infância era referido como contexto extra-materno, o que aconteceu com 177 crianças (30.5\% da amostra), verificava-se que, para cerca de metade das crianças, era o único contexto frequentado. Por outro lado, a educadora foi também a única pessoa referida como pessoa responsável pela criança no contexto. Os pais das crianças deste grupo eram os que tinham um nível educativo mais elevado (mais de nove anos de escolaridade) e profissões mais diferenciadas.

A casa de familiares foi referida para 162 crianças, e as pessoas responsáveis nomeadas eram as avós e, menos frequentemente, outros familia- 
res. A casa da criança foi um local referido para 151 crianças, sendo os responsáveis nomeados os irmãos, as avós e, menos frequentemente, outros familiares e as empregadas domésticas. Quando as casas de outrem eram referidas como local de cuidados, o que aconteceu com 55 crianças, as pessoas responsáveis eram a ama e os vizinhos. Finalmente, o parque era um local nomeado para 26 crianças, sendo outras as pessoas responsáveis ou, muito raramente, ninguém.

Os contextos de cuidados informais são apontados como os únicos contextos frequentados na rotina semanal pelas mães com habilitações mais baixas (menos de 9 anos de escolaridade) e com horários de trabalho muito dilatados, sendo que cerca de $60 \%$ das mães deste grupo passam mais de 45 horas por semana fora de casa.

Quando, na rotina semanal da criança, existia mais do que um contexto extra-familiar, houve necessidade de definir o contexto principal, operacionalizado como aquele onde a criança passava mais tempo, durante a semana.

No grupo de 410 crianças que frequentavam mais do que um contexto extra-materno, o contexto principal era, em $41 \%$ dos casos, o jardim-de-infância, seguindo-se a avó, quer na sua própria casa, quer em casa da criança (cerca de $40 \%$ dos casos). Quando nomeado na rotina semanal, o jardim-de-infância era quase sem excepções (apenas nove casos o foram), o contexto mais relevante. A avó, quer na sua própria casa quer em casa da criança, apesar de constituir o contexto referido com mais frequência, não era aquele onde as crianças passavam mais tempo durante a semana, aparentando funcionar como um contexto complementar. De facto, de entre as $49 \%$ mães que nomeavam a avó como contexto de cuidados semanal, esta só era o contexto principal em $34 \%$ dos casos, funcionando como segundo contexto e complemento ao jardim-de-infância para 63 crianças.

A ama foi o terceiro contexto mais relevante, sendo o contexto principal para $8 \%$ das crianças, seguido de familiares, quer em casa da criança, quer na própria casa.

Foi também obtida informação relativamente ao tempo que as crianças passavam no contexto principal, verificando-se que o número de horas variava entre um mínimo de 10 horas e um máximo de 60 horas, o que, em média, corresponde a um mínimo de 2 horas por dia e a um máximo de 12 horas diárias. Foi possível verificar que cerca de $32 \%$ destas crianças passava entre 31 e 45 horas no contexto principal, e que cerca de $30 \%$ o faziam entre 46 e 60 horas, o que constitui uma quantidade de tempo considerável, tendo em conta que em muitos casos existiam ainda contextos adicionais.

Relativamente aos custos inerentes à frequência dos contextos, verificou-se que cerca de $36 \%$ das famílias não pagavam os contextos extra-maternos. Quanto à distância diária percorrida pelas crianças na deslocação 
para os contextos, cerca de $35.5 \%$ das crianças da amostra viviam a menos de 500 metros de distância do contexto extra-materno, e que apenas 7,8\% das crianças percorriam mais de três quilómetros. A maior parte das deslocações era feita a pé (47\%), e o automóvel era o meio de transporte mais comummente utilizado (15.4\%), surgindo o autocarro escolar em apenas $12.2 \%$ dos casos.

\section{Rotina diária}

A fim de conhecer a forma como as crianças passavam um dia típico, recolheu-se informação, para cada hora do dia e da noite, relativamente ao local onde estava a criança, à pessoa responsável e à presença de outras crianças e adultos, nomeadamente da mãe e do pai.

Com vista a identificar os contextos frequentados ao longo do dia, e tendo em conta a forma como foi operacionalizada a noção de contexto de socialização, a informação relativa ao local e à pessoa responsável foi cruzada, verificando-se que 56 contextos apareciam com expressão numérica. Usando como procedimento uma análise factorial de correspondências, esta informação foi simplificada, destacando-se os períodos horários mais relevantes e os contextos mais frequentados que lhes estavam associados.

O período nocturno, entre as 20h e as 8 horas, corresponde aproximadamente ao jantar e noite, encontrando-se as crianças em casa com os pais, e assumindo-se a mãe com frequência como a principal responsável, apesar do pai se encontrar normalmente também presente.

Os períodos entre as $9 \mathrm{~h}$ e 12 horas e entre as $14 \mathrm{~h}$ e 17 horas, correspondem essencialmente à frequência de contextos extra-maternos, coincidindo com o horário escolar/laboral, sendo típicos o jardim de infância, a casa dos avós, a casa da criança com os avós e a ama. No período da tarde era frequente o contexto em casa com irmão mais velho ou em casa sozinha. Igualmente típico, embora menos frequente, era o parque/jardim/rua com a mãe, usado provavelmente por crianças que passavam o dia todo apenas com a mãe.

Os períodos entre as $8 \mathrm{~h}$ e 9 horas e as $17 \mathrm{~h}$ e 20 horas correspondem a momentos de transição, ou seja, coincidem com a mudança de contextos. As crianças encontram-se essencialmente em casa com um dos pais ou com outra pessoa, na rua em transição com um dos pais, no parque/jardim/rua com a mãe ou com irmão e, ainda, no emprego da mãe ou do pai.

\section{Discussão}

É importante salientar o carácter essencialmente descritivo destes dados, e o seu enquadramento temporal, já que correspondem a uma realidade vigente há cerca de 20 anos atrás, pelo que o seu valor reside sobretudo 
nas questões que levantam e como eventual base para análise das transformações que entretanto se produziram.

A articulação dos contextos frequentados pelas crianças na rotina semanal e na rotina diária sugerem, à partida, ideias bastante distintas. A rotina semanal das crianças parece ser relativamente estável, no sentido em que a maioria das crianças permanece em casa ou frequenta apenas um ou dois contextos extra-maternos. Contudo, a análise da rotina diária revela uma maior quantidade e diversidade de contextos frequentados pelas crianças ao longo do dia (56 contextos), apontando para uma menor regularidade das rotinas.

Esta discrepância entre a análise horizontal (ao longo da semana) e a análise vertical (ao longo do dia) tem a ver essencialmente com três aspectos. Em primeiro lugar, a exclusão, na rotina semanal, de toda a informação referente aos contextos maternos. Em segundo lugar, a exclusão, também na rotina semanal, das situações de carácter transitório e ocasional, dado que apenas foram considerados os contextos frequentados pela criança, pelo menos duas horas, numa base regular. Em terceiro lugar, a rotina diária, sendo exaustiva, permitiu a identificação da totalidade dos contextos frequentados pela criança, independentemente do seu carácter mais ou menos sistemático e da sua duração.

A discrepância observada é pois justificável e seria esperada. Assim, se a rotina semanal nos permite identificar contextos relevantes para análise posterior, nomeadamente em termos de promoção da qualidade de vida das crianças, a rotina diária permitirá identificar o número e o tipo de transições e, entre outras análises possíveis, estabelecer comparações de carácter internacional. Constituem assim duas abordagens complementares que, no seu todo, possibilitam uma análise ecológica, que se traduz na reconstituição de padrões de itinerários típicos para as crianças portuguesas desta faixa etária e na sua relação com factores diversos do meio familiar e cultural próximos.

Um dado que merece relevo prende-se com o tempo passado por semana em contextos extra-maternos. De facto, verifica-se que uma percentagem importante de crianças $(62 \%)$ passa mais de 30 horas por semana (média de seis horas por dia) com outros que não os pais, e de entre estas, cerca de 30\% estão mesmo mais de 45 horas (média de nove horas por dia) nesta situação. Estes dados chamam a atenção para a organização da rotina das mães, cuja ocupação profissional parece impedir um contacto mais prolongado com os filhos em idade tão precoce. Por outro lado, torna-se evidente a necessidade de garantir a qualidade dos contextos extra-familiares frequentados pelas crianças de quatro anos, dada a grande quantidade de tempo que elas aí passam. Se tal garantia será eventualmente possível tratando-se de contextos formais (o que acontece nesta amostra em $30 \%$ das crianças), o mesmo não acontece no que respeita aos contextos informais. 
O IEA-PPP constituiu um projecto implementado entre 1986 e 1990 na Faculdade de Psicologia e de Ciências da Educação da Universidade do Porto, sob a direcção dos Professores Joaquim Bairrão e Maria Isolina Borges. Este projecto permitiu descrever as situações de cuidados prestados às crianças de idade pré-escolar, levantar questões e desenvolver metodologias de investigação que se revelaram fundamentais no desenvolvimento do Centro de Psicologia do Desenvolvimento e Educação da Criança. A apresentação deste projecto e de alguns dos seus resultados neste número especial ${ }^{9}$ pretendeu caracterizar de forma sucinta a realidade vivenciada pelas crianças de quatro anos numa época em que escasseava informação de cariz quantitativo, mas também e principalmente, prestar tributo ao papel pioneiro assumido pelo Prof. Bairrão no contexto da pesquisa em educação pré-escolar. Neste papel destacam-se, a adopção e implementação de um referencial teórico ecológico-sistémico, que desde então tem norteado muitos dos trabalhos de investigação desenvolvidos pelo grupo, e a inserção da sua equipa em redes de investigação internacional, a maior parte das quais perdura até ao presente.

\section{Referências}

Bairrão, J., Barbosa, M. A., Borges, M. I., Cruz, O., \& Macedo-Pinto, I. (1989). Care and education for children under age six in Portugal. In P. Olmsted \& D. Weikart (Eds.), How nations serve young children: Profiles of child care and education in 14 countries (pp. 273-302). Ypsilanti: The High Scope Press.

Bronfenbrenner, U. (1979). The ecology of human development: Experiments by nature and design. Cambridge, M. A.: Harvard University Press.

Bronfenbrenner, U. (1993). The ecology of cognitive development: Research models and fugitive findings. In R. H. Wosniak \& Fischer (Eds.), Scientific environments (pp. 3-44). Hillsdale, NJ: Erlbaum.

Bronfenbrenner, U., \& Morris, P. (1998). The ecology of developmental processes. In W. Damon \& M. Lerner (Eds.), Handbook of child psychology. Vol 1(pp. 993-1028). New York: Wiley \& Sons.

Katz, L., Crahay, M., Tietze, W., Wolf, R., Rossbach, H.-G., \& Indrasuta, C. (1984). Preprimary Study. International Association for the Evaluation of Educational Achievement. Manuscrito não publicado.

Tietze, W., \& Rossbach, H.-G. (1984, September). A conceptual framework for the analysis of socialization environments. European Conference of the International Society for the Study of Behavioural Development. Groninger, Holanda.

\footnotetext{
${ }^{9}$ Por lapso, este artigo não foi incluído no vol. XXIII, 2 (2009), Número especial de Homenagem a Joaquim Bairrão.
} 